Scientific journal

PHYSICAL AND MATHEMATICAL EDUCATION Has been issued since 2013

Науковий журнал

ФІЗИКО-МАТЕМАТИЧНА ОСВІТА

Видається з 2013.

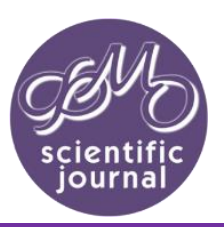

p-ISSN 2413-1571

e-ISSN 2413-158X

DOI: $10.31110 / 2413-1571$

https://fmo-journal.org/

DOI 10.31110/2413-1571-2021-032-6-008

УДК [37.091.313:004:005.591.1]:7.012

\section{ШЛЯХИ ВДОСКОНАЛЕННЯ ДИЗАЙН-ОСВІТИ У КОНТЕКСТІ СТРАТЕГІЇ ЦИФРОВОЇ ТРАНСФОРМАЦІї ОСВІТИ I НАУКИ УКРАЇНИ}

\author{
Ганна ЧЕМЕРИС \\ Запорізький національний університет, Україна \\ anyta.chemeris@gmail.com \\ https://orcid.org/0000-0003-3417-9910 \\ Ганна БРЯНЦЕВА \\ Запорізький національний університет, Україна \\ bganna@ukr.net \\ https://orcid.org/0000-0002-9689-8497 \\ Олександр БРЯНЦЕВ \\ Запорізький національний університет, Україна \\ albrypaper@gmail.com \\ https://orcid.org/0000-0002-9220-0653
}

\section{WAYS TO IMPROVE DESIGN EDUCATION IN THE CONTEXT OF THE STRATEGY OF DIGITAL TRANSFORMATION OF EDUCATION AND SCIENCE OF UKRAINE}

\author{
Hanna CHEMERYS \\ Zaporizhzhia National University, Ukraine \\ anyta.chemeris@gmail.com \\ https://orcid.org/0000-0003-3417-9910 \\ Hanna BRIANTSEVA \\ Zaporizhzhia National University, Ukraine \\ bganna@ukr.net \\ https://orcid.org/0000-0002-9689-8497 \\ Olexandr BRIANTSEV $\square$ \\ Zaporizhzhia National University, Ukraine \\ albrypaper@gmail.com \\ https://orcid.org/0000-0002-9220-0653
}

\begin{tabular}{|c|}
\hline цाя \\
\hline 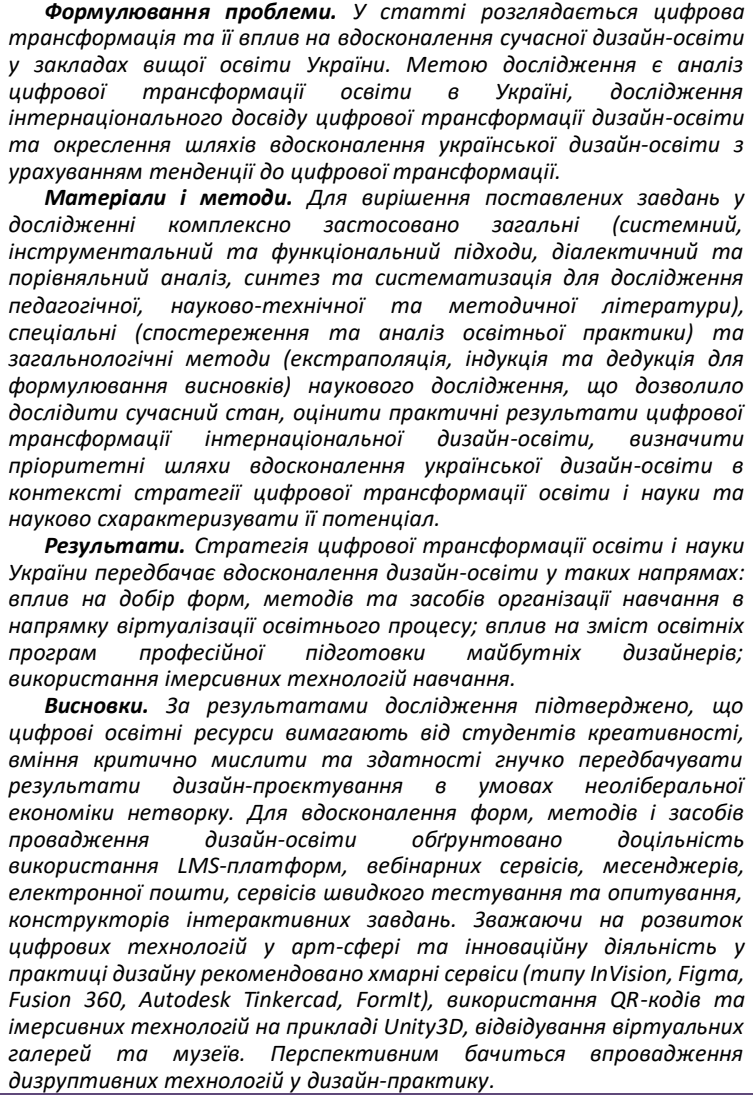 \\
\hline
\end{tabular}

\section{ABSTRACT}

Formulation of the problem. The article considers the digital transformation and its impact on the improvement of modern design education in higher education institutions of Ukraine. The aim of the study is to analyze the digital transformation of education in Ukraine, study the international experience of digital transformation of design education and outline ways to improve Ukrainian design education, taking into account the trend towards digital transformation.

Materials and methods. To solve the tasks in the study comprehensively used general (systemic, instrumental and functional approaches, dialectical and comparative analysis, synthesis and systematization for the study of pedagogical, scientific, technical and methodological literature), special (observation and analysis of educational practice) and general methods (extrapolation). , induction and deduction to draw conclusions) of scientific research, which allowed to study the current state, evaluate the practical results of digital transformation of international design education, identify priority ways to improve Ukrainian design education in the context of digital transformation of education and science and scientifically characterize its potential.

Results. The strategy of digital transformation of education and science of Ukraine provides for the improvement of design education in the following areas: influence on the selection of forms, methods and means of organizing education in the direction of virtualization of the educational process; influence on the content of educational programs of professional training of future designers; use of immersive learning technologies.

Conclusions. The study confirmed that digital educational resources require students to be creative, think critically and be able to flexibly anticipate the results of design in a neoliberal economy. To improve the forms, methods and means of design education, the expediency of using LMS-platforms, webinar services, messengers, e-mail, quick testing and survey services, designers of interactive tasks is substantiated. Given the development of digital technologies in the art field and innovative activities in design practice, cloud services (such as InVision, Figma, Fusion 360 , Autodesk Tinkercad, Form/t), the use of $Q R$ codes and immersive technologies such as Unity3D, virtual galleries and museums are recommended. The introduction of disruptive technologies in design practice is promising.

\section{Для цитування:}

For citation:
Чемерис Г., Брянцева Г., Брянцев О. Шляхи вдосконалення дизайн-освіти у контексті стратегії цифрової трансформації освіти і науки України. Фізикоматематична освіта, 2021. Том 32. № 6. С. 49-56. DOI: https://doi.org/10.31110/2413-1571-2021-032-6-008 чемемис, Чемерис, Г., Брянцева, Г., \& Брянцев, О. (2021). Шляхи вдосконалення дизайн-освіти у нонт
математична освіта, 32(6). 49-56. https://doi.org/10.31110/2413-1571-2021-032-6-008 Chemerys, H., Briantseva, H., \& Briantsev, O. (2021). Ways to improve design education in the context of the strategy of digital transformation of education and science of Ukraine. Physical and Mathematical Education, 32(6), 49-56. https://doi.org/10.31110/2413-1571-2021-032-6-008 improve design education in the context of the strategy of digital transformation of education and science of Ukraine]. Fizyko-matematychna osvita - Physical and Mathematical Education, 32(6), 49-56. https://doi.org/10.31110/2413-1571-2021-032-6-008

Corresponding author (C) H. Chemerys, H. Briantseva, O. Briantsev, 2021 
КлючовІ словА: діджиталізачія; чифрова трансформація; дизруптивні технології; вища освіта; дизайн-освіта; професійна підготовка майбутніх дизайнерів.
KEYWORDS: digitalization; digital transformation; disruptive technologies; higher education; design education; professional training of future designers.

\section{ВСТУП}

Постановка проблеми. Позитивна динаміка економічного розвитку світового та українського ринку дизайнерських послуг, яка спостерігається впродовж останніх років, активізує тенденцію зростання та розвитку ринку предметного дизайну як інтернаціонального явища в Україні. Також в реаліях розвитку сучасного світу та динамічності потреб ринку праці в умовах інформаційного суспільства цифрова трансформація стає закономірним етапом розвитку системи освіти в цілому та дизайн-освіти, зокрема. У сучасних закладах вищої освіти (ЗВО) створюється електронне середовище, яке охоплює всіх учасників процесу - від ректора до випускника закладу, і всі етапи - від вступу абітурієнтів до якісного удосконалення освітніх програм, які забезпечують професійну підготовку майбутніх фахівців, зокрема, й дизайнерів. Водночас треба зазначити, що цифровізація не позбавляє мистецьку освіту індивідуальних, особистісних та практико-орієнтованих підходів.

Відповідно до зрушень на ринку праці здійснюється реформування загальногалузевого контексту, концептуальних положень та основних вимог до організації сучасної дизайн-освіти, які знайшли висвітлення в низці законодавчих документів України (Національна стратегія Індустрії 4.0, Проєкт Концепції цифрової трансформації освіти і науки на період до 2026 року та ін.).

Зважаючи на стратегію цифрової трансформації вищої освіти, важливо віднайти оптимальні та ефективні шляхи вдосконалення системи дизайн-освіти з урахуванням ефективного формування професійно важливих навичок майбутніх дизайнерів. Зважаючи на результати системного дослідження стану розвитку дизайну в Україні, яке було проведено агенцією економічного розвитку PPV Knowledge Networks в рамках проєкту «Моніторинг розвитку дизайну в Україні» програми «УКМ: Український культурний монітор» за підтримки Українського культурного фонду у 2019 р. (Стан розвитку дизайну в Україні, 2019), виокремлено ряд проблем сучасної дизайн-освіти України:

- дизайнерам-практикам бракує бізнес-компетентностей, при цьому і формальна і неформальна освіта не приділяють їм достатньої уваги; наявна освіта недостатня для розуміння дизайнерами потреб ринку та ведення бізнесу;

- слабка технічна база формальної освіти, використання застарілих технологій, універсальність спеціальності, мала кількість спеціалізацій;

- чималий обсяг навчальних годин обіймають мистецькі дисципліни в академічному поданні без врахування динаміки дизайн-змін;

- завелика у програмах підготовки частка теоретичної складової, через що виникає реальна загроза невідповідності підготовки випускників потребам ринку;

- невиправдана інструменталізація навчальних матеріалів освіти через зацікавленість у швидкому комерційному результаті і як небажаний наслідок - фрагментарність отриманих знань.

За цих умов постає нагальна потреба переосмислення контексту сучасної дизайн-освіти зважаючи на цілі цифрової трансформації освіти та науки України та її узгодження з екосистемою ринку дизайнерських послуг, зокрема через імплементацію у навчальний процес дизруптивних технологій (Мунк \& Ґілен, 2020; ґілен, 2019).

Аналіз актуальних досліджень. Проблематика дослідження зумовила здійснення аналізу публікацій сучасних закордонних вчених, які розглядали шляхи та проблеми цифрової трансформації в суспільстві та освіті (Kaneet al., 2015; Snow al., 2017; Morakanyane al., 2017; Westerman al., 2014; Bharadwaj al., 2014; Hess, Matt al., 2016; Singh \& Hess, 2017; Klötzer \& Pflaum, 2017; Matt al., 2015 та ін.). Окремі питання цифрової трансформації освітньої політики, висвітлені у працях (Смирна, 2021; Чемерис \& Брянцев, 2021; Чемерис \& Брянцева, 2021; Chemerys et al., 2021). Для дослідження сучасного стану рівня цифровізації у дизайн-освіті було розглянуто доробок провідних науковців у царині дизайну, а саме теоретичні основи мистецької i, зокрема, дизайнерської освіти висвітлені в працях Є. Антоновича, В. Даниленка, В. Кардашова, О. Олексюк, О. Отич, В. Прусака, О. Рудницької, В. Тименка; вплив мистецтва на розвиток особистості в педагогічному процесі був предметом уваги досліджень таких вчених, як І. Зязюн, Г. Васянович, О. Гончаренко, Н. Ничкало, В. Фіголь; у контексті мистецької освіти проблема дизайну висвітлюється в наукових доробках Є. Маркова, Л. Масол, Н. Миропольської, О. Ростовського, О. Рудницької, Г. Тарасенка. Питання використання інформаційних технологій у дизайн освіті знайшли відображення у дослідженнях (Black, 2002; Browning, 2006; Degennaro \& Mak, 2002-2003; Flood \& Bamford, 2007; Gude, 2007; Leonard \& Leonard 2006; Lu, 2005; Mayo, 2007). Здійснений аналіз доробку вчених уможливив висновок щодо наявності потреби в пошуку оптимальних шляхів вдосконалення української дизайн-освіти з урахуванням стратегії цифрової трансформації освіти і науки.

Мета статті є дослідження шляхів трансформації дизайн-освіти з урахуванням світових тенденцій до цифрової трансформації освіти.

\section{ТЕОРЕТИЧНІ ОСНОВИ ДОСЛІДЖЕННЯ}

3 огляду на загальносвітову тенденцію дистанційна освіта $€$ важливим елементом довгострокового стратегічного розвитку та цифрової трансформації закладів вищої освіти. Впровадження цифрових технологій впливає не лише на інновації в оснащенні навчального процесу закладу освіти, а й на модернізацію освітньої діяльності, необхідної в умовах глобалізації сучасного наукового світу.

За результатами аналізу щорічного звіту про стан дистанційного навчання у вищій освіті США («Ten Years of Tracking Online Education in the United States») у 2002 році менш ніж половина респондентів з академічного середовища США вважали дистанційну освіту необхідною умовою для розвитку 3ВО. У 2012 році вже майже 69,1\% представників навчальних закладів США відзначили, що дистанційна освіта $\epsilon$ важливим елементом довгострокового стратегічного розвитку зВо. Частка 
студентів, які взяли хоча б один дистанційний курс, у 2013 році становить 32\% від загальної кількості респондентів (Allen \& Seaman, 2013). За даними Міжнародної ради відкритої та дистанційної освіти (The International Council for Open and Distance Education (ICDE)), Інституту ЮНЕСКО для безперервного навчання (UIL) (The UNESCO Institute for Lifelong Learning (UIL)) та StudyPortals (SP) європейський освітній ринок демонструє схожі тенденції. За даними звіту «Вплив дистанційної освіти на навчання дорослих» (Impact of Distance Education on Adult Learning) лише 20\% закладів вищої освіти Європи, які брали участь в опитуванні, не пропонують жодних дистанційних курсів, 9\% пропонують отримання виключно дистанційної освіти. Слід зазначити, що майже всі Скандинавські університети пропонують форму дистанційної освіти. Половина закладів вищої освіти Європи впроваджує дистанційний формат як доповнення до основного навчального процесу, ще $20 \%$ будують навчання на основі змішаної моделі, яка набуває дедалі більшої популярності (EADTU).

Однак через карантинні заходи з 2019-2020 н.р. дистанційні технології організації навчального процесу стали єдино можливими. Державною службою якості освіти України було проведено дослідження щодо стану використанням технологій дистанційного навчання в умовах запровадженого загальнонаціонального карантину. В анкетуванні було задіяно 28391 респондентів - 22367 здобувачів вищої освіти та 6024 науково-педагогічних працівників ЗВО всіх типів та форм власності. За результатами опитування біло виявлено, що майже 45\% опитаних викладачів використовували дистанційні технології регулярно або за планом, майже $40 \%$ інколи користувалися ними і 15\% опитаних взагалі не використовували дистанційні технології для організації навчального процесу до впровадження карантинних обмежень (SQE, 2020). Зокрема, до звіту Національного агентства із забезпечення якості освіти увійшли результати дослідження провадження дистанційної практики в мистецькій освіті. Згідно з матеріалами звіту було виявлено, що працівники вищої мистецької освіти, які вимушено були поставлені в умови віртуального спілкування зі студентом у процесі дистанційного навчання, змінили ставлення не лише до практики трансляції знань, а й до особистісно забарвленого відчутяя дистанції між собою, своїми емоціями та індивідуальністю студента. Тобто дистанція збереглася, але набула віртуального характеру. Це не суперечить тенденціям у комунікативних процесах, як в інформаційному просторі, так і, власне, міжлюдських стосунків (Смирна, 2021).

При цьому дизайн-освіта має справу не скільки зі смисловими, як з принципово просторовими явищами у навчанні, тому певною мірою опирається віртуальній дистанції між викладачем і студентом, адже спрямовує зусилля на актуальне зняття цієї дистанції, тобто перетворює просторові смисли на змістові, а не навпаки (Degennaro \& Mak, 20022003; Gregory, 2009).

\section{МЕТОДИ ДОСЛІДЖЕННЯ}

Для вирішення поставлених завдань у дослідженні комплексно застосовано взаємопов'язані методи наукового дослідження, а саме: загальні (системний, інструментальний та функціональний підходи, діалектичний та порівняльний аналіз, синтез та систематизація для дослідження педагогічної, науково-технічної та методичної літератури), спеціальні (спостереження та аналізу освітньої практики) та загальнологічні методи (екстраполяція, індукція та дедукція для формулювання висновків проведеного дослідження). Обрані методи дослідження дозволили дослідити сучасний стан, оцінити практичні результати цифрової трансформації інтернаціональної дизайн-освіти, визначити пріоритетні шляхи вдосконалення української дизайн-освіти в контексті стратегії цифрової трансформації освіти і науки та науково схарактеризувати її потенціал.

\section{РЕЗУЛЬТАТИ ДОСЛІДЖЕННЯ}

Першим кроком на шляху вдосконалення системи дизайн-освіти $є$ перегляд форм, методів та засобів, що використовуються для організації освітнього процесу в напрямку його віртуалізації. Цифрові технології $\epsilon$ дієвим механізмом різнобічного розвитку закладу освіти та освітнього процесу, а спектр сучасних цифрових ресурсів надає можливість здійснювати освітній процес дистанційно за індивідуальним навчальним планом в будь-який час (за принципом 7/24 - сім днів на тиждень і 24 години на добу) і будь-де та надають можливість керувати власними результатами навчання, вибудовуючи власну навчальну траєкторію, в тому числі для здобувачів з обмеженими можливостями. Це в свою чергу трансформує соціальну парадигму життєдіяльності людей - відкриває можливості для отримання та вдосконалення знань, розширення своїх професійних компетентностей та перепідготовку в будь-який момент свого життя. Сучасні цифрові ресурси та інформаційно-комунікаційні технології забезпечують швидкий обмін останніми розробками, досвідом та знаннями, надають можливість дистанційного і змішаного навчання, розширюють цифрові бібліотеки, підвищують академічну мобільність та розширюють спільні дослідження, інтегрують у міжнародний науковий та освітній простір, дозволяючи адаптуватися до сучасних соціокультурних та економічних умов і зберети свої унікальні якості та конкурентні переваги, формуючи єдине електронне інформаційно-освітнє середовище. Практика дистанційного та змішаного навчання створює поле необмежених освітніх можливостей, що покращує якість освіти кожної людини, незалежно від місця проживання та навичок, але відповідно до її інтересів та можливостей.

Дизайн-освіта потребує особистісного контакту викладача зі здобувачем освіти під час освітнього процесу. Цифрова трансформація дизайн-освіти не позбавляє здобувачів цього контакту, а, навпаки, дозволяє уникнути втрат часу, який зазвичай йде на підготовку до групових занять на користь практичної підготовки. Студент, займаючись самостійно тривалим пошуком, може швидко засвоїти теоретичний матеріал, відвідати цифрову бібліотеку, ознайомитися 3 прикладами робіт сучасних прогресивних дизайнерів, отримати рекомендації викладача дистанційно, при цьому витрачаючи вільний час на концентровану практичну діяльність. Студенти можуть вибирати курси відповідно до власних потреб, з огляду на авторитет і практичний доробок викладача, популярності дизайн-напрямку, актуального інтересу тощо. Основними критеріями позитивного впливу цифровізації на навчальний процес $€$ підвищення навчальних досягнень здобувачів, активізація проєктної діяльності та самостійна наукова та творча робота студентів, підвищення фахового інтересу до профільних дисциплін.

Для ефективної організації освітнього процесу у попередніх дослідженнях (Чемерис \& Брянцев, 2021) було визначено програмні засоби, які $\epsilon$ універсальними для організації цифрового освітнього середовища. Найбільшу 
популярність серед закладів вищої освіти для формування цифрового освітнього середовища мали LMS-платформи, а саме LMS Moodle. Також було ви значено доцільні програмні засоби для проведення онлайн-лекцій і консультацій (Google Meet, Hangouts, Skype, Zoom, BigBlueButton), для швидкої комунікації та консультацій: месенджери (Messenger, Viber, WhatsApp), для підготовки інтерактивних завдань (Learning Apps, Miro) та для організації зворотного зв'язку (Kahoot, Triventy, Mentimer).

Однак, зважаючи на низку особливостей організації освітнього процесу підготовки майбутніх дизайнерів, варто враховувати специфіку окремих компонентів освітньої програми та здійснювати добір доцільних програмних засобів вузької фахової спрямованості. Наведемо можливості застосування дібраних програмних засобів відповідно до освітніх компонентів на прикладі освітньої програми “Графічний дизайн" (Чемерис \& Брянцев, 2021; Чемерис \& Брянцева, 2021): для організації навчання ОK "Веб-дизайн", “UI/UX дизайн” можна використовувати хмарний сервіс Figma або сервіс InVision для створення елементів інтерфейсу.

При опануванні ОK “3D моделювання" та “Гейм дизайн” доцільним є використання хмарних 3D-систем, а саме Fusion 360, безкоштовний додаток Autodesk Tinkercad, інструмент Formlt для створення 3D-ескізів чи для моделювання ігрового оточення. Для підтримки процесу дистанційного або змішаного навчання для викладання освітніх компонентів “Історія мистецтв", “Історія дизайну" та “Арт проєкти” доцільно використовувати доступ до віртуальних та інтерактивних музеїв і експозицій (в період пандемії значна кількість світових музеїв, таких, як Лувр, Париж, Франція; Музей Соломона Гуггенхайма, Нью-Йорк, США; Національна галерея мистецтв, Вашингтон, США; Британський мүзей, Лондон, Великобританія; Національний музей природної історії, Вашинпон, США; Метрополітен-музей, Нью-Йорк, США; Національний палац-музей, Тайбей, Тайвань; Музеї Ватикану, Рим, Італія забезпечили віртуальне представлення власних експозицій). Зокрема цікавим для професійної підготовки майбутніх дизайнерів $є$ проєкт Google Arts \& Culture - інтернетплатформа, яка надає доступ до понад 35000 арт-творів з високою роздільною здатністю, панорамних зйомок із залів музеїв та має розвинену потужну базу візуальних кросвордів на знання мистецьких творів (Чемерис \& Брянцев, 2021).

Другим кроком на шляху вдосконалення системи дизайн-освіти в контексті цифрової трансформації $є$ перегляд змісту професійної підготовки майбутніх дизайнерів з урахуванням динаміки змін сучасного ринку праці, викликів цифрової економіки та потреб цифрового суспільства. Тому, зважаючи на стратегію цифрової трансформації вищої освіти важливо віднайти оптимальні та ефективні шляхи вдосконалення системи дизайн-освіти з урахуванням ефективного сформування професійно важливих навичок майбутніх дизайнерів.

Орієнтирами у трансформаційних процесах змістовності вищої освіти в цілому та дизайн-освіти зокрема стають світові стандарти, згідно з якими у дизайн-освіті доцільно активно використовувати програмовані, інтерактивні та проблемні методи навчання. Серед проблемних методів навчання особливе місце посідають методи проєктноорієнтованого навчання, що надають змогу залучати студентів до процесу набуття фахових знань, умінь і навичок за допомогою дослідницької діяльності. Дослідницька діяльність базується на комплексних, реальних технічних проблемах і ретельно опрацьованих завданнях. Під час проєктної діяльності майбутні дизайнери мають можливість втілювати авторські задуми у формі дизайнерських проєктів. Це дозволить студентам оволодіти знаннями та сформувати навички у практичній діяльності, пройти технологічний алгоритм від зародження інноваційної ідеї до створення цілісного продукту, а також навчитися презентувати його. Тому, наприклад, розглядаючи проєктну діяльність для опанування тривимірного моделювання, майбутні дизайнери мають поєднати набуті знання з таких дисциплін, як “Рисунок”, “Живопис", “Історія мистецтв і архітектури”, “Основи композиції”, “Основи кольорознавства” та “Пластична анатомія”.

Використання інтерактивних методів можливе з використанням QR кодів (Quick Response Code, 2D Code) та сприйнятям/поданням їх як елементів дизайну. Поширення QR-кодів стало можливим завдяки мобільним технологіям, зокрема, використанню смартфону в освітньому процесі (за допомогою камери та мобільного додатку): для Android - це 2D-код, Barcode Scanner, Barcode2file, Elinext UPC, Google Goggles, I-Nigma, ixMAT Scanner, NeoReader, QuickMark, QR Droid; для Java - Kaywa Reader, I-Nigma, UpCode; для Symbian OS-BeeTag, I-Nigma, Kaywa reader, NeoReader, Nokia barcode reader, UpCode, QuickMark; для Windows Mobile - I-Nigma, QuickMark та ін.

Швидкого поширення набули імерсивні технології («X-реальностей» (XR) або середовищ з додатковим ефектом присутності), внаслідок чого актуалізувалися технології віртуальної (Virtual Reality, VR), доповненої (Augmented Reality, AR) i змішаної реальності (Mixed Reality, MR). Це потужні технології, які дозволяють замінити реальне житя на сприйнятя віртуального життя, штучним чином стимулюючи наші почуття і обманюючи наше тіло в прийнятті іншої версії реальності (LaValle, 2017). Доповненою реальністю називається технологія, що створює ілюзію взаємодії цифрових 3D-компонентів 3 фізичним середовищем (при цьому створюється відчуття, що тривимірні об'єкти насправді існують). У той час як під віртуальною реальністю розуміється процес створення повністю цифрового світу, в який може зануритися користувач, відміна технологій доповненої реальності в тому, що вони поєднують реальний світ з віртуальними артефактами, об'єктами або даними. Хоча доповнена та віртуальна реальність часто групуються через їх очевидну схожість, доповнена реальність, як правило, робить більший акцент на вдосконаленні існуючих середовищ, а не на зануренні користувача в абсолютно нові. Технологія віртуальної реальності найкраще підходить для використання у відеоіграх і проектуванні застосунків для різноманітних гаджетів, а також останнім часом набула широкого розповсюдження у дизайні поліграфічної продукції, реклами, моушн-графіки тощо. Зважаючи на це можливо стверджувати, що обізнаність майбутніх дизайнерів з технологіями XR значно підвищить їх конкурентоздатність на ринку праці, що вказує на актуальність імплементації вивчення імерсивних технологій у процес професійної підготовки дизайнерів. На доцільність використання імерсивних технологій вказує всесвітній прогноз на 2020-2025 рр. у звіті Goldman Sachs' (2016), де продемонстровано приріст ринку імерсивних технологій за різними сегментами. Зважаючи на бурхливий розвиток імерсивних технологій у сучасному діджиталізованому суспільстві зазначимо, що їх доцільно впровадити в освітній процес, як засіб інноваційних комунікацій, які зарекомендували себе як найбільш перспективні, та такі, що будуть активно розвиватись у найближчі часи (Chemerys et al., 2021a; Chemerys et al., 2021b). В якості найбільш перспективного середовища для роботи з доповненою та віртуальною реальностями розглядаємо платформу Unity3D у поєднанні з набором програмного забезпечення Vuforia SDK, який включає інструменти імерсивних технологій та підтримується на мобільних пристроях: планшетах, смартфонах та окулярах AR для iOS, Android тa UWP (Windows). 
Загальна тенденція ринку віртуальної і доповненої реальності як інноваційних інструментів комунікації спричинила поштовх до розвитку вакантних пропозицій на ринку праці та пропозицій конкурентоспроможних зарплат як одна з найбільш високооплачуваних індустрій. Це своєю чергою спричинило передумови до реорганізації змісту навчання майбутніх дизайнерів. Підвищення прибутку при використанні зазначених технологій, максимальне залучення уваги, новизна у використанні, перспективи та можливості в дизайні реклами, поліграфічних видань та маркетингу - це лише частина від усіх можливих позитивних ефектів від використання доповненої і віртуальної реальності у професійній діяльності майбутніх дизайнерів. Тому наприклад, в процесі вивчення освітнього компоненту “Мультимедійні технології” необхідно звертати увагу на вивчення можливостей імерсивних технологій у якості створення ілюстрацій з доповненою реальність для ілюстрування книжкового видання, рекламної продукції тощо.

Отже, стратегія цифрової трансформації освіти і науки України передбачає вдосконалення дизайн-освіти у таких напрямах: вплив на добір форм, методів та засобів організації навчання в напрямку віртуалізації освітнього процесу; вплив на зміст освітніх програм професійної підготовки майбутніх дизайнерів, використання імерсивних технологій.

\section{ОБГОВОРЕННЯ}

3 метою підготовки фахівців у галузі дизайну, які будуть затребуваними на ринку праці, головним завданням 3ВО $\epsilon:$ навчити здобувачів вчитися та бути готовими до змін і роботи зі складними проєктами; швидко опановувати прогресивні практики та сучасні спеціалізовані програмні засоби; бути здатними до самоосвіти та освоєння суміжних професій; відстежуючи тенденції ринку праці. Зміст освіти у ЗВО повинен бути побудований таким чином, аби перевищувати наявну номенклатуру компетентностей для забезпечення випереджувальної професійної підготовки.

Базуючись на здійсненому дослідженні відзначаємо персоналізацію освіти та їі варіативність з формуванням індивідуальної освітньої траєкторії. Ця перевага зумовлена перевагами цифрового освітнього середовища, управління та контролю за освітнім процесом, а також розширенням можливостей отримати гідну та якісну освіту для широкого кола людей, незалежно від їх попереднього рівня освіти та здібностей. Можливість реалізації проблемних методів навчання із залученням інтерактивних ресурсів. Пасивне сприйняття інформації на лекціях замінюється особистим залученням студентів до навчального процесу проблемними завданнями, кейсами та іншими формами навчання в цифровому освітньому середовищі. Використання сучасних та прогресивних освітніх цифрових засобів навчання, запроваджених шляхом цифрової трансформації освіти, дозволяє якщо не вирівняти успішність, то помітно підвищити ії. Завдяки цифровій трансформації вища освіта набуває широкого поширення. Підвищення ступеня самостійності та відповідальності здобувачів під час виконання завдань. Опанування студентами навичок роботи з сучасними програмними засобами та опанування дизруптивними технологіями, що підвищить конкурентоспроможність, як майбутніх дизайнерів. Розширення можливостей до міжнародної мобільності за допомогою засобів дистанційного навчання. Цифрова трансформація та сучасні комунікаційні технології сприяють підвищенню адаптації закладу вищої мистецької освіти до цільової аудиторії та конкурентоспроможності на ринку освітніх послуг.

Зважаючи на те, що для сталого розвитку дизайн-освіти та запобігання девальвації дизайнерської творчості необхідна інноваційна спрямованість у процесі вибудови змісту освітнього процесу перспективним бачиться дослідження впливу дизруптивних технологій на еволюцію практики дизайну. Зокрема, у дослідженні (Гардабхадзе, 2019) дизруптивні технології розглядаються як “інноваційні технології, що діють руйнівно на традиційні процеси, ведуть до девальвації певних професійних компетентностей і навіть змінюють деякі галузі економіки, але натомість несуть людству небачені раніше можливості". У визначенні, наведеному у праці (Бесараб та ін., 2019) дефініція “дизруптивні технології" розглядається як сучасні технологічні тенденції, зумовлені процесами глобалізації, та являють собою ключовими драйверами їі здійснення; знаходяться в тісному взаємозв'язку з інноваціями і залежать від їх впливу на рівень якості, як існуючої, так і інноваційно-нової продукції. Тому під час перегляду змісту професійної підготовки перспективним бачиться активна імплементація дизруптивних технологій у практику навчання. Наприклад, опанування освітнього компоненту “Тривимірне моделювання" може бути орієнтовано на вивчення технології тривимірного друку.

\section{ВИСНОВКИ ТА ПЕРСПЕКТИВИ ПОДАЛЬШОГО ДОСЛІДЖЕННЯ}

Цифрова трансформація дизайн-освіти в сучасному світі $є$ незворотною, тому потребує пильної уваги професійної спільноти для подальшого ії вдосконалення. Попри неминучі недоліки системи освіти, використання цифрового освітнього середовища у мистецькій освіті підтвердило свою ефективність, що відкриває нові перспективи для розвитку дизайн-освіти і дозволяє вивести вітчизняну дизайн-освіту на якісно новий рівень.

Цифрове середовище об'єктивно спонукає студента упорядковувати наявні у нього ресурси даних під власні потреби, раціонально й усвідомлено орієнтуватися в потоках цифрової інформації, критично їі оцінювати й використовувати, обробляти та інтегрувати в умовах зміненого контексту. Чинниками, які визначають зростання навчальних досягнень майбутніх дизайнерів, є інновації, що скеровують студентів до сталого і водночас неперервного розвитку, удосконалення професійних компетентностей, оволодіння новими видами діяльності. Цифрові освітні ресурси вимагають від студентів креативності, вміння критично мислити та здатності гнучко передбачувати результати дизайнпроєктування в умовах неоліберальної економіки нетворку. Цифрова трансформація породжує доступність інформації в різних її формах, передусім візуальній, що зменшує непродуктивні і часозатратні пошуки актуального та цікавого контенту, водночас істотно, у рази збільшуючи швидкість його постобробки. Цифрова трансформація дизайн-освіти розширюе спектр технологій, які опановують студенти, а доступність навчальних матеріалів у дистанційній формі надає можливість навчатися в будь-який зручний час.

У дослідженні на основі практичного досвіду та теоретичних досліджень описано можливості застосування сучасних програмних засобів для формування цифрового освітнього середовища майбутніх дизайнерів в умовах дистанційного або змішаного навчання. Для вдосконалення та перегляду форм, методів і засобів провадження дизайн-освіти було обгрунтовано доцільність використання LMS-платформи Moodle та її модулів; вебінарних сервісів Google Meet, Skype, 
Zoom, Moodle BigBlueButton; месенджерів Messenger, Hangouts, Viber, WhatsApp; електронної пошти; сервісів швидкого тестування та опитування Kahoot, Triventy, Mentimer; конструктори інтерактивних завдань Learning Apps та Miro. Зважаючи на розвиток цифрових технологій у арт-сфері та інноваційну діяльність у практиці дизайну для перегляду змісту дизайн-освіти було запропоновано професійно орієнтованих хмарних сервісів InVision, Figma, Fusion 360, Autodesk Tinkercad, Formlt; застосування технологій QR-кодів; вивчення імерсивних технологій на прикладі Unity3D у поєднанні з набором програмного забезпечення Vuforia SDK; відвідування віртуальних галерей та музеїв. Окреслені шляхи вдосконалення форм, засобів, методів та змісту дизайн-освіти за рахунок впровадження дизруптивних технології нададуть можливість інтеграції закладів вищої мистецької освіти у міжнародний науково-освітній простір та сприятимуть розвитку української економіки.

Напрям подальших досліджень доцільно спрямувати на перегляд освітніх програм з метою організації нових моделей дизайн-освіти, які базуються на цифровій трансформації.

\section{СПИСОК ВИКОРИСТАНИХ ДЖЕРЕЛ}

1. Бесараб, С.О., Клименко, С. М., \& Люшенко, О. І. (2019). Дизруптивні інновації як драйвери четвертої промислової революції. Strategies for Entrepreneurship for Sustainable Development of Small and Medium-Sized Innovative Entrepreneurship : International Conference (c. 97-101). Riga : Baltic International Academy. https://ir.kneu.edu.ua:443/handle/2010/35683

2. Гардабхадзе, І. А. (2019). Креативність дизруптивних технологій як тренд-фактор управління сталим розвитком постцифрового суспільства. Траєкторії сталого розвитку українського суспільства: особистість і кульутра : зб. наукових доп. V міжнар. наук.практ. конф. (с. 22-26). Маріуполь : МДУ. http://91.250.23.215/jspui/bitstream/123456789/1402/1/traektorii_stalogo_2019_ch1.pdf

3. Ґілен, П. (2019). Культура та інші фундаменталізми. Харків: IST Publishing.

4. Інформаційно-аналітична довідка про результати опитування щодо стану використання технологій дистанційного навчання у закладах вищої освіти України (2020). Державна служба якості освіти України (SQE). https://old.sqe.gov.ua/index.php/ukua/hovyny/1214-rezultaty-opytuvannya-shchodo-dystantsiynoho-navchannya-u-zakladakh-vyshchoyi-osvity-v-umovakh-karantynu

5. Мунк, М., \& Ґілен, П. (2020). Близькість. Мистецтво та освіта після COVID-19. Харків: IST Publishing.

6. Національна стратегія Індустрії 4.0. Ключові технології цифрових трансформацій.https://industry4-0-ukraine.com.ua

7. Про Національну програму інформатизації: Закон України від 4 лютого 1998 року № 74/98-ВР. https://zakon.rada.gov.ua/laws/show/74/98-вр

8. Проект Концепції цифрової трансформації освіти і науки на період до 2026 року. Міністерство освіти і науки України. https://mon.gov.ua/ua/news/koncepciya-cifrovoyi-transformaciyi-osviti-i-nauki-mon-zaproshuye-do-gromadskogo-obgovorennya

9. Смирна, Л. (2021). Дистанційна практика в мистецькій освіті. Річний звіт Національного агентства із забезпечення якості вищої освіти / За заг. ред. С. Квіта та О. Єременко. К. : Національне агентство із забезпечення якості вищої освіти. https://naqa.gov.ua/wpcontent/uploads/2021/02/Річний-звіт-2020.pdf

10. Стан розвитку дизайну в Україні (на прикладі графічного та предметного дизайну). Звіт за результатами дослідження (2019). https://uaculture.org/wp-content/uploads/2020/01/232708_analitychnyj-zvit_monitoryng-rozvytku-dyzajnu-v-ukrayini.pdf

11. Україна 2030Е - країна з розвинутою цифровою економікою (2018). Український інститут майбутнього. https://strategy.uifuture.org/kraina-z-rozvinutoyu-cifrovoyu-ekonomikoyu.html

12. Цифрова адженда України - 2020. Цифрові тренди. Концептуальні засади. https://ucci.org.ua/uploads/files/58e78ee3c3922.pdf

13. Цифрова стратегія України 2020: успішна інтеграція країни у глобальний ринок (2017). Новини економіки і законодавства. https://ckp.in.ua/events/16407

14. Чемерис, Г., \& Брянцев, О. (2021). Добір програмного забезпечення для формування цифрового освітнього середовища майбутніх дизайнерів в умовах змішаного навчання. Педагогіка формування творчої особистості у вищій і загальноосвітній школах: зб. наук. пр., 78, 261-265. Запоріжжя: КПУ. https://doi.org/10.32840/1992-5786.2021.78.47

15. Чемерис, Г., \& Брянцева, Г. (2021). Фронезис як системоутворювальний фактор дизайн-освіти. Педагогіка формування творчої особистості у вищій і загальноосвітній школах: зб. наук. пр., 76(3), 151-155. Запоріжжя: КПУ. https://doi.org/10.32840/19925786.2021.76-3.27

16. Allen, I. E., \& Seaman, J. (2013). Changing course: Ten years of tracking online education in the United States. Babson Park, MA: Babson Survey Research Group and Quahog Research Group. http://www.onlinelearningsurvey.com/reports/changingcourse.pdf

17. Bharadwaj, A., Omar, A. El Sawy, Pavlou, A. Paul, \& Venkatraman, N. (2013). Digital Business Strategy: Toward a Next Generation of Insights. MIS Quarterly, 37 (2), 471-482. https://misq.org/misq/downloads/download/editorial/581/

18. Black, J. (2002). Topsy-turvy teacher-student relationships: An examination of digital multimedia teaching and learning. Dissertation Abstracts International, 63, 6.

19. Black, J., \& Browning, K. (2011). Creativity in Digital Art Education Teaching Practices. Art Education, 64(5), 19-34. https://doi.org/10.1080/00043125.2011.11519140

20. Browning, K. (2006). Digital applications in elementary visual arts: A case study in Ontario and Newfoundland schools. Canadian Review of Art Education, 33(1), 25-41.

21. Chemerys, H., Briantsev, O., Briantseva, H., \& Vynogradova A. (2021). Combined Capabilities of AR Technology and POP-UP Constructions for Designing Books for Children. Yearbook of Moving Image Studies «Augmented Images: Trilogy of Synthetic Realities II». Marburg : Buechner Verlag.

22. Chemerys, H., Vynogradova, A., Briantseva, H., \& Sharov S. (2021). Strategy for Implementing Immersive Technologies in the Professional Training Process of Future Designers. Journal of Physics: Conference Series, 1933, art. no. 012046. https://doi.org/10.1088/1742$6596 / 1933 / 1 / 012046$

23. Degennaro, A., \& Mak, B. (2003). A diffusion model for computer art in education. Journal of Educational Technology Systems, 31(1), 5-18. https://doi.org/10.2190/B69J-FDFR-UKBY-4LEL

24. Distance education in European higher education (2014). Report 1 (of 3). https://idealprojectblog.files.wordpress.com/2013/11/ideal_report_final.pdf

25. European Association of Distance Teaching Universities (EADTU). https://eadtu.eu/

26. Flood, A., \& Bamford, A. (2007). Manipulation, simulation, stimulation: The role of art education in the digital age. International Journal of Education through Art, 3(2), 91-102. https://doi.org/10.1386/eta.3.2.91_1

27. Gregory, D. (2009). Boxes with fire: Wisely integrating learning technologies into the art classroom. Art Education, 62(3), 47-54. https://doi.org/10.1080/00043125.2009.11519020

28. Gude, O. (2007). Principles of possibility: Considerations for a 21st-century art \& culture curriculum. Art Education, 60(1), 6-17. https://doi.org/10.1080/00043125.2007.11651621 
29. Hess, T., Matt, C., Benlian, A., \& Wiesböck F. (2016). Options for Formulating a Digital Transformation Strategy. MIS Quarterly Executive, 15(2), 103-119.

30. Horn, M. (2011). Keynote Speaker. Disruptive Class: How Disruptive Innovation Will Change the Way the World. NBOA, Symposium Report. https://www.nboa.org/HigherLogic/System/DownloadDocumentFile.ashx?DocumentFileKey=e247025f-65d9-4c61-a853-c8c4febe1119

31. Kane, G. C. (2015). Is Your Business Ready for a Digital Future? MIT Sloan Management, 56(4), 37-44. https://sloanreview.mit.edu/article/isyour-business-ready-for-a-digital-future/

32. Kane, G. C., Palmer, D., Phillips, A. N., Kiron, D., \& Buckley N. (2015). Strategy, not technology, drives digital transformation. MIT Sloan Management. https://sloanreview.mit.edu/projects/strategy-drives-digital-transformation/

33. Klötzer, Ch., \& Pflaum, A. (2017). Toward the Development of a Maturity Model for Digitalization within the Manufacturing Industry's Supply Chain. Proceedings of the 50th Hawaii International Conference on System Sciences (HICSS) 2017, At Hilton Waikoloa Village, HI, USA, 50, 4210-4219. https://doi.org/10.24251/HICSS.2017.509

34. LaValle, S. M. (2017). Virtual Reality. Cambridge: Cambridge University Press.

35. Leonard, L., \& Leonard, P. (2006). Leadership for technology integration: Computing the reality. The Alberta Journal of Educational Research, 52(4), 212-224.

36. Lu, Li-Fen (2005). Preservice art teacher negative attitudes and perceptions of computer-generated art imagery: Recommendations for preservice art education programs. Visual Arts Research, 31(1), 60, 89-102.

37. Matt, Ch., Hess, T., \& Benlian, A. (2015). Digital Transformation Strategies. Business \& Information Systems Engineering, 57(5), 339-343. https://doi.org/10.1007/s12599-015-0401-5

38. Mayo, S. (2007). Implications for art education in the third millennium: Art technology integration. Art Education, 60(3), 45-51. https://doi.org/10.1080/00043125.2007.11651644

39. Morakanyane, R., Grace, A., \& O'Reilly, Ph. (2017). Conceptualizing Digital Transformation in Business Organizations: A Systematic Review of Literature. Proceedings of the 30th Bled eConference Digital Transformation -From Connec2013\% 2016)ting Things to Transforming Our Lives. Bled, Slovenia. https://doi.org/10.18690/978-961-286-043-1.30

40. Singh, A., \& Hess, T. (2017). How Chief Digital Officers Promote the Digital Transformation of their Companies. MIS Quarterly Executive, 16(1), 1-17.

41. Snow, Ch. C., Fjeldstad, Ø. D., \& Langer, A. M. (2017). Designing the digital organization. Journal of Organization Design, 6, art.no. 7. https://doi.org/10.1186/s41469-017-0017-y

42. The Education Commission Report (2015). The Learning Generation. https://report.educationcommission.org/the-four-transformations/

43. Virtual \& Augmented Reality Augmented - Understanding the Race for the Next Computing Platform I Goldman Sachs' Jan. 2016. https://www.goldmansachs.com/insights/pages/technology-driving-innovation-folder/virtual-and-augmented-reality/report.pdf

44. Westerman, G., Bonnet, D., \& McAfee, A. (2014). Leading Digital: Turning Technologyinto Business Transformation. Harvard Business Review Press.

\section{REFERENCES (TRANSLATED AND TRANSLITERATED)}

1. Besarab, S. O., Klymenko, S. M., \& Lyushenko, O. I. (2019). Dyzruptyvni innovatsiyi yak drayvery chetvertoyi promyslovoyi revolyutsiyi [Disruptive innovations as drivers of the fourth industrial revolution]. Strategies for Entrepreneurship for Sustainable Development of Small and Medium-Sized Innovative Entrepreneurship : International Conference, Riga : Baltic International Academy, 97-101. https://ir.kneu.edu.ua:443/handle/2010/35683 (in Ukrainian).

2. Hardabkhadze, I. A. (2019). Kreatyvnist' dyzruptyvnykh tekhnolohiy yak trend-faktor upravlinnya stalym rozvytkom posttsyfrovoho suspil'stva [Creativity of disruptive technologies as a trend factor in managing sustainable development of post-digital society]. Traiektorii staloho rozvytku ukrainskoho suspilstva: osobystist i kulutra : zb. naukovykh dop. $V$ mizhnar. nauk.-prakt. konf. - Trajectories of sustainable development of Ukrainian society: personality and culture: coll. scientific add. V International scientific-practical conf. (pp. 22-26). Mariupol: MSU. http://91.250.23.215/jspui/bitstream/123456789/1402/1/traektorii_stalogo_2019_ch1.pdf (in Ukrainian).

3. Gilen, P. (2019). Culture and other fundamentalisms. Kharkiv: IST Publishing. (in Ukrainian).

4. Informatsiyno-analitychna dovidka pro rezul'taty opytuvannya shchodo stanu vykorystannya tekhnolohiy dystantsiynoho navchannya u zakladakh vyshchoyi osvity Ukrayiny [Information and analytical information on the results of the survey on the state of use of distance learning technologies in higher education institutions of Ukraine] (2020). Derzhavna sluzhba yakosti osvity Ukrayiny - State Service for Education Quality of Ukraine. https://old.sqe.gov.ua/index.php/uk-ua/hovyny/1214-rezultaty-opytuvannya-shchodo-dystantsiynohonavchannya-u-zakladakh-vyshchoyi-osvity-v-umovakh-karantynu (in Ukrainian).

5. Munch, M., \& Gilen, P. (2020). Intimacy. Art and education after COVID-19. Kharkiv: IST Publishing. (in Ukrainian).

6. Natsional'na stratehiya Industriyi 4.0. Klyuchovi tekhnolohiyi tsyfrovykh transformatsiy [National Industry Strategy 4.0. Key technologies of digital transformations]. https://industry4-0-ukraine.com.ua (in Ukrainian).

7. Pro Natsional'nu prohramu informatyzatsiyi: Zakon Ukrayiny vid 4 lyutoho 1998 № 74/98-VR [On the National Informatization Program: Law of Ukraine of February 4, 1998 № 74/98-VR]. URL: https://zakon.rada.gov.ua/laws/show/74/98-Bp (in Ukrainian).

8. Proekt Kontseptsiyi tsyfrovoyi transformatsiyi osvity i nauky na period do 2026 roku [Draft Concept of digital transformation of education and science for the period up to 2026]. Ministerstvo osvity i nauky Ukrainy - Ministry of Education and Science of Ukraine. https://mon.gov.ua/ua/news/koncepciya-cifrovoyi-transformaciyi-osviti-i-nauki-mon-zaproshuye-do-gromadskogo-obgovorennya (in Ukrainian).

9. Smyrna, L. (2021). Dystantsiyna praktyka v mystets'kiy osviti [Distance practice in art education]. Richnyy zvit Natsional'noho ahent.stva iz zabezpechennya yakosti vyshchoyi osvity - Annual report of the National Agency for Quality Assurance in Higher Education / Za zah. red. S. Kvita ta O. Yeremenko. K. : National Agency for Quality Assurance in Higher Education. https://naqa.gov.ua/wpcontent/uploads/2021/02/Річний-звіт-2020.pdf (in Ukrainian).

10. Stan rozvytku dyzaynu v Ukrayini (na prykladi hrafichnoho ta predmetnoho dyzaynu). Zvit za rezul'tatamy doslidzhennya [The state of design development in Ukraine (on the example of graphic and subject design). Report on the results of the study]. https://uaculture.org/wpcontent/uploads/2020/01/232708_analitychnyj-zvit_monitoryng-rozvytku-dyzajnu-v-ukrayini.pdf (in Ukrainian).

11. Ukrayina 2030E - krayina z rozvynutoyu tsyfrovoyu ekonomikoyu [Ukraine 2030E is a country with a developed digital economy] (2018). Ukrainskyi instytut maibutnoho - Ukrainian Institute of the Future. https://strategy.uifuture.org/kraina-z-rozvinutoyu-cifrovoyuekonomikoyu.html (in Ukrainian).

12. Tsyfrova adzhenda Ukrainy - 2020. Tsyfrovi trendy. Kontseptualni zasady [Digital Agenda of Ukraine - 2020. Digital trends. Conceptual principles]. https://ucci.org.ua/uploads/files/58e78ee3c3922.pdf (in Ukrainian).

13. Tsyfrova stratehiya Ukrayiny 2020: uspishna intehratsiya krayiny u hlobal'nyy rynok [Ukraine's Digital Strategy 2020: Successful Integration of the Country into the Global Market] (2017). Novyny ekonomiky $i$ zakonodavstva - Economics and legislation news. https://ckp.in.ua/events/16407 (in Ukrainian). 
14. Chemerys, H., \& Briantsev, O. (2021). Dobir prohramnoho zabezpechennya dlya formuvannya tsyfrovoho osvitn'oho seredovyshcha maybutnikh dyzayneriv v umovakh zmishanoho navchannya [Selection of software for the formation of digital educational environ ment for future designers in a blended learning environment]. Pedahohika formuvannia tvorchoi osobystosti u vyshchii i zahalnoosvitnii shkolakh: zb. nauk. pr. - Pedagogy of formation of creative personality in higher and general education schools: coll. Science, 76(3), 151-155. Zaporizhzhya : CPU. https://doi.org/10.32840/1992-5786.2021.78.47 (in Ukrainian).

15. Chemerys, H., \& Briantseva, H. (2021). Fronezys yak systemoutvoryuval'nyy faktor dyzayn-osvity [Fronesis as a system-forming factor of design education]. Pedahohika formuvannia tvorchoi osobystosti u vyshchii i zahalnoosvitnii shkolakh: zb. nauk. pr. - Pedagogy of formation of creative personality in higher and general education schools: coll. Science, 76 (3), 151-155. Zaporizhzhya : CPU. https://doi.org/10.32840/1992-5786.2021.76-3.27 (in Ukrainian).

16. Allen, I. E., \& Seaman, J. (2013). Changing course: Ten years of tracking online education in the United States. Babson Park, MA: Babson Survey Research Group and Quahog Research Group. http://www.onlinelearningsurvey.com/reports/changingcourse.pdf

17. Bharadwaj, A., Omar, A. El Sawy, Pavlou, A. Paul, \& Venkatraman, N. (2013). Digital Business Strategy: Toward a Next Generati on of Insights. MIS Quarterly, 37 (2), 471-482. https://misq.org/misq/downloads/download/editorial/581/

18. Black, J. (2002). Topsy-turvy teacher-student relationships: An examination of digital multimedia teaching and learning. Dissertation Abstracts International, 63, 6 .

19. Black, J., \& Browning, K. (2011). Creativity in Digital Art Education Teaching Practices. Art Education, 64(5), 19-34. https://doi.org/10.1080/00043125.2011.11519140

20. Browning, K. (2006). Digital applications in elementary visual arts: A case study in Ontario and Newfoundland schools. Canadian Review of Art Education, 33(1), 25-41.

21. Chemerys, H., Briantsev, O., Briantseva, H., \& Vynogradova A. (2021). Combined Capabilities of AR Technology and POP-UP Constructions for Designing Books for Children. Yearbook of Moving Image Studies «Augmented Images: Trilogy of Synthetic Realities I/». Marburg : Buechner Verlag.

22. Chemerys, H., Vynogradova, A., Briantseva, H., \& Sharov S. (2021). Strategy for Implementing Immersive Technologies in the Professional Training Process of Future Designers. Journal of Physics: Conference Series, 1933, art. no. 012046. https://doi.org/10.1088/1742$6596 / 1933 / 1 / 012046$

23. Degennaro, A., \& Mak, B. (2003). A diffusion model for computer art in education. Journal of Educational Technology Systems, 31(1), 5-18. https://doi.org/10.2190/B69J-FDFR-UKBY-4LEL

24. Distance education in European higher education (2014). Report 1 (of 1 ) https://idealprojectblog.files.wordpress.com/2013/11/ideal_report_final.pdf

25. European Association of Distance Teaching Universities (EADTU). https://eadtu.eu/

26. Flood, A., \& Bamford, A. (2007). Manipulation, simulation, stimulation: The role of art education in the digital age. International Journal of Education through Art, 3(2), 91-102. https://doi.org/10.1386/eta.3.2.91_1

27. Gregory, D. (2009). Boxes with fire: Wisely integrating learning technologies into the art classroom. Art Education, 62(3), 47-54. https://doi.org/10.1080/00043125.2009.11519020

28. Gude, O. (2007). Principles of possibility: Considerations for a 21st-century art \& culture curriculum. Art Education, 60(1), 6-17. https://doi.org/10.1080/00043125.2007.11651621

29. Hess, T., Matt, C., Benlian, A., \& Wiesböck F. (2016). Options for Formulating a Digital Transformation Strategy. MIS Quarterly Executive, 15(2), 103-119.

30. Horn, M. (2011). Keynote Speaker. Disruptive Class: How Disruptive Innovation Will Change the Way the World. NBOA, Symposium Report https://www.nboa.org/HigherLogic/System/DownloadDocumentFile.ashx?DocumentFileKey=e247025f-65d9-4c61-a853-c8c4febe1119

31. Kane, G. C. (2015). Is Your Business Ready for a Digital Future? MIT Sloan Management, 56(4), 37-44. https://sloanreview.mit.edu/article/isyour-business-ready-for-a-digital-future/

32. Kane, G. C., Palmer, D., Phillips, A. N., Kiron, D., \& Buckley N. (2015). Strategy, not technology, drives digital transformation. MIT Sloan Management. https://sloanreview.mit.edu/projects/strategy-drives-digital-transformation/

33. Klötzer, Ch., \& Pflaum, A. (2017). Toward the Development of a Maturity Model for Digitalization within the Manufacturing Industry's Supply Chain. Proceedings of the 50th Hawaii International Conference on System Sciences (HICSS) 2017, At Hilton Waikoloa Village, HI, USA, 50, 4210-4219. https://doi.org/10.24251/HICSS.2017.509

34. LaValle, S. M. (2017). Virtual Reality. Cambridge: Cambridge University Press.

35. Leonard, L., \& Leonard, P. (2006). Leadership for technology integration: Computing the reality. The Alberta Journal of Educational Research, 52(4), 212-224.

36. Lu, Li-Fen (2005). Preservice art teacher negative attitudes and perceptions of computer-generated art imagery: Recommendations for preservice art education programs. Visual Arts Research, 31(1), 60, 89-102.

37. Matt, Ch., Hess, T., \& Benlian, A. (2015). Digital Transformation Strategies. Business \& Information Systems Engineering, 57(5), 339-343. https://doi.org/10.1007/s12599-015-0401-5

38. Mayo, S. (2007). Implications for art education in the third millennium: Art technology integration. Art Education, 60(3), 45-51. https://doi.org/10.1080/00043125.2007.11651644

39. Morakanyane, R., Grace, A., \& O'Reilly, Ph. (2017). Conceptualizing Digital Transformation in Business Organizations: A Systematic Review of Literature. Proceedings of the 30th Bled eConference Digital Transformation -From Connec2013\% 2016)ting Things to Transforming Our Lives. Bled, Slovenia. https://doi.org/10.18690/978-961-286-043-1.30

40. Singh, A., \& Hess, T. (2017). How Chief Digital Officers Promote the Digital Transformation of their Companies. MIS Quarterly Executive, 16(1), 1-17.

41. Snow, Ch. C., Fjeldstad, $\varnothing$. D., \& Langer, A. M. (2017). Designing the digital organization. Journal of Organization Design, 6, art.no. 7. https://doi.org/10.1186/s41469-017-0017-y

42. The Education Commission Report (2015). The Learning Generation. https://report.educationcommission.org/the-four-transformations/

43. Virtual \& Augmented Reality Augmented - Understanding the Race for the Next Computing Platform | Goldman Sachs' Jan. 2016. https://www.goldmansachs.com/insights/pages/technology-driving-innovation-folder/virtual-and-augmented-reality/report.pdf

44. Westerman, G., Bonnet, D., \& McAfee, A. (2014). Leading Digital: Turning Technologyinto Business Transformation. Harvard Business Review Press.

\section{$(\mathrm{CC}) \mathrm{BY}-\mathrm{NC}-\mathrm{SA}$}

This work is licensed under Creative Commons Attribution-NonCommercial-ShareAlike 4.0 International License. 